OPEN ACCESS

Edited by:

Wei Guo,

Nanjing University, China

Reviewed by:

M. Rashad Massoud, University Research Co.,

United States

Zhongquan $\mathrm{Li}$,

Nanjing University, China

${ }^{*}$ Correspondence:

Yingwu Li

liyingwu@ruc.edu.cn

tThese authors have contributed equally to this work and share first

authorship

Specialty section: This article was submitted to Occupational Health and Safety,

a section of the journal

Frontiers in Public Health

Received: 11 August 2021 Accepted: 20 January 2022

Published: 23 February 2022

Citation:

Dong M, Zhang T, Li Y and Ren Z (2022) The Effect of Work Connectivity

Behavior After-Hours on Employee Psychological Distress: The Role of

Leader Workaholism and

Work-to-Family Conflict.

Front. Public Health 10:722679.

doi: 10.3389/fpubh.2022.722679

\section{The Effect of Work Connectivity Behavior After-Hours on Employee Psychological Distress: The Role of Leader Workaholism and Work-to-Family Conflict}

\author{
Mingchao Dong ${ }^{1 \dagger}$, Tianlu Zhang ${ }^{1 \dagger}$, Yingwu $L^{1,2 *}$ and Zhengzheng Ren ${ }^{1}$ \\ ${ }^{1}$ Department of Psychology, Renmin University of China, Beijing, China, ${ }^{2}$ The Laboratory of Department of Psychology, \\ Renmin University of China, Beijing, China
}

Background: The work connectivity behavior after-hours (WCBA) has become increasingly intense among Chinese employees in recent years, especially in the rapidly developed internet industry. This has made the after-hours work connectivity behavior, a popular topic in the organizational psychology field. Based on boundary theory, we explored the mechanism of after-hour work connectivity behavior on employees' psychological distress and identified the work-to-family conflict (WFC) as mediator. Besides, leader characteristics are essential environmental variables and always play as moderators, among which leader workaholism is prevalent in the internet industry. However, the impact of leader workaholism on employees' behavior is still inconsistent and even contradictory. Thus, this study further examines the moderating effect of leader workaholism between the after-hour work connectivity behavior and employees' psychological distress.

Methods: We conducted a multitime, multisource questionnaire survey in Internet companies in China. Before collecting the data, all participants were assured that their responses would be confidential and used only for academic research. At time 1, the team leader rated his or her workaholism, and team members rated WCBA. At time 2 (3 weeks later), team members were asked to complete the questionnaire containing scales of WFC, psychological distress. The two rounds of data collection resulted in 211 matched team leader-team member responses. We performed a path analysis using Mplus 7.4.

Results: Both the duration and frequency of WCBA can positively predict employees' psychological distress through WFC (the mediating effect $=0.628,95 \% \mathrm{Cl}=[0.593$, 0.663]). Specifically, WCBA can increase the level of WFC, which leads to the employees' psychological distress further. Leader workaholism can negatively moderate the relationship between WCBA and WFC, further moderating the mediating effect of WFC. 


\begin{abstract}
Conclusions: Work-to-family conflict played as a mediator in the relationship between WCBA and employees' psychological distress. These results may be helpful to recognize the negative effect of WCBA and the role of leader workaholism in the relationship.
\end{abstract}

Keywords: work connectivity behavior after-hours, work-to-family conflict, leader workaholism, psychological distress, mental health

\section{INTRODUCTION}

The development of information technology has intensified the competition in the capital market and made the Internet field a high-pressure industry, which has created more overtime work and more flexible working systems. Some organizations hope that their employees can keep online for their job during offwork hours so that they could be prepared to work at any time. This typical work connectivity behavior after-hours (WCBA) often leads to individuals' physical fatigue and psychological distress. It is also an invasion of family time, which leads to the breakdown of work-family balance. Drawing on the work-family boundary theory, work-to-family conflict (WFC) can cause employees' psychological distress. However, there is seldom literature exploring the relationship between WCBA and employees' psychological distress from the work-family boundary perspective. This study aims to address this gap by introducing WFC as a mediator based on work-family boundary theory. Besides, leader characteristics are important environmental variables. In the Chinese internet industry, leader workaholism is prevalent. How this environmental variable works on WFC and employees' psychological distress are also one question of this study.

\section{THEORETICAL BACKGROUND AND HYPOTHESIS}

\section{WCBA and Psychological Distress of Employees}

In this study, WCBA refers to employees participating in work in any place outside of working hours. According to the boundary theory, the impact of work connectivity behavior on individual health during non-working hours can be divided into work and family interfaces. On the work interface, employees will suffer from physical and mental exhaustion, emotional exhaustion, job burnout (1), a decrease in job satisfaction when they experience longtime non-working hours' connections. They would even have the psychological tendency to try to disengage from work (2). Ragsdale and Hoover (3) investigated the relationship between WCBA and employees' emotional exhaustion and found that using Internet communication tools (ICTs) to deal with work during non-working hours increases individual emotional exhaustion and role stress. At the family interface, according to the allostatic load theoretical model (4), dealing with excessive work pressure for a long time will have dual impacts on employees' mental and physical health and eventually increase the occurrence of depression and cardiovascular diseases. Li et al. (5) used the job demand and control (JDC) model to study the employees of a company in state grid. They found that the increase of working hours per week had a positive prediction on occupational stress and depressive symptoms measured by the PHQ-9 scale. When employees worked more than $60 \mathrm{~h}$ per week, their health risks increased significantly, and excessive or frequent connectivity during nonworking time consumes a large number of mental resources and affects selfrecovery (6). Overall, being occupied by work in the leisure time would hurt individuals physical and mental health, which is also known as psychological distress. Thus, we propose the following hypothesis:

Hypothesis 1: WCBA is positively related to employee psychological distress.

\section{Mediating Role of WFC}

Through the lens of work-family boundary theory, time-based conflict may occur when the time spent on ICTs outside of work hours makes them no longer able to participate in their family roles and activities because individuals cannot allocate time to work and family time. Besides, the use of work-related ICT outside of working hours may trigger stress spillages from the work area to the home. Continuous connectivity makes it more difficult for people to dissociate and disengage from work at home, thus impeding the recovery of work stress outside of working hours (7), and stress-based conflict can happen.

Studies have shown that frequent WCBA induces ontogenesis of WFC (8). WFC leads to job dissatisfaction, turnover intention, and stress, and WFC plays a mediating role between the flexibility of work schedule and work stress (9). Liang and Chen (10) explored the influencing factors of fatigue among 3,603 employees of 35 Internet enterprises. They found that the use of Internet communication technologies and tools positively predicted the level of work stress. In contrast, occupational stress factors brought by work stress were negatively correlated with employees' mental health. Some scholars have further investigated the differences in WFC on employees of different genders and found that the traditional male and female division of labor still affects the amount of family role sharing. WFC is significant in predicting depression symptoms of female training physicians (11). Moreover, the psychological distress caused by WFC is higher for women than for male individuals (11). Therefore, we propose the following hypothesis:

Hypothesis 2: WFC has a mediating effect on WCBA and employee psychological distress.

\section{Moderating Role of Leader Workaholism}

According to the previous studies, workaholism refers to the phenomenon of employees who become overindulging in work so that their health and family life are harmed (12). Based on this 
definition, this study defines a workaholic leader as individuals who are physically overworked and cognitively addicted to work. Workaholism tends to stimulate a tense and competitive work environment and develop negative interactions with employees. WCBA tends to cause resentment, anger, and other negative emotions in individuals, thus causing WFC (13). According to Andreassen et al. (14), leaders with high levels of workaholism tend to vent their negative emotions to their employees and therefore raise employees' aggression, which would increase negative emotional expression in the family and trigger WFC. In addition, workaholic leaders tend to give vague or unreasonable task requirements to employees, which consumes employees' time and energy, so employees of workaholic leaders are more likely to work overtime, which ultimately increases the possibility of WFC. A leader with high-level workaholism may strengthen the relationship between WCBA and WFC (15), which thereafter damages mental health. Therefore, we propose the following hypothesis:

Hypothesis 3a: Leader workaholism positively moderates the relationship between WCBA and WFC. When the leader's workaholism tendency is high, the positive prediction of WFC by WCBA is strengthened, whereas weakened.

However, the existing literature has not reached a consensus on whether workaholic leaders play a positive or negative moderating role between WCBA and WFC. Pan (16) found that when employees are encountering WFC, leader workaholism could provide necessary social support. Employees who experience high levels of social support at work (17) are more likely to continue working after working hours because they enjoy the interpersonal support and work assistance from colleagues. Therefore, the support brought by workaholic leaders may weaken the impact of WCBA on WFC. Thus, an auxiliary hypothesis is proposed:

Hypothesis 3b: Leader workaholism negatively moderates the relationship between WCBA and WFC. When the leader's workaholism tendency is high, the positive prediction of WFC by WCBA is weakened, whereas strengthened.

Combining hypotheses 2 and 3, a moderated mediating effect model is proposed:

Hypothesis 4: Leader workaholism moderates the indirect effect between WCBA and employee psychological distress via WFC. This indirect effect can be moderated by the leader's workaholic tendencies.
The theoretical model of this study is shown in Figure 1.

\section{METHODS}

To test the hypothesis, we used the questionnaire method.

\section{Participants}

Participants include both team leaders and their direct employees in four internet companies located in Beijing, Guangzhou, Shanghai, and Hangzhou.

\section{Procedure}

The data were collected in two waves, from March to April in 2021. First, we contacted several HR managers in four internet companies to ask their support to release the paper questionnaires in their companies. The questionnaire contains demographic information and was attached with a letter explaining the purpose of the survey, voluntary participation, and guaranteed confidentiality. At time 1, the workaholism scale was sent to team leaders in four companies, and one direct team member of the leader rated his/her WCBA. At time 2 (three weeks later), these team members were recontacted to complete the scales of psychological distress and WFC. All scales were clearly explained with unified and standardized instructions given by researchers. A total of 1,200 questionnaires were sent in the first wave, which include 600 leader versions and 600 employees' versions. The second wave contained 600 questionnaires only for employees. All participants were asked to fill out the questionnaire and put it back into an envelope that was collected by our research team.

\section{Measurement}

Each variable in the self-administered survey was measured using a multiitem scale, each of which was adopted from relevant prior research. As all our participants were Chinese, we followed the double-blind backtranslation procedure (18) to translate all items into Chinese. To avoid translation ambiguity, each item was translated by professional translators. The internal consistency of each scale was verified through Cronbach's alpha.

\section{Work Connectivity Behavior After-Hours (WCBA)}

Work connectivity behavior after-hours was assessed by a 13item scale of $\mathrm{Wu}$ et al. (15) recommended by Richardson and

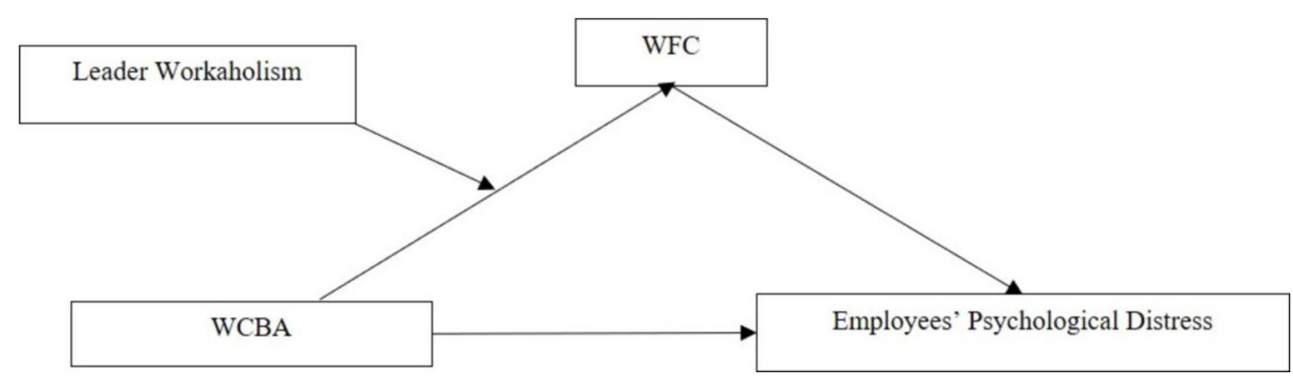

FIGURE 1 | Research theoretical model. 
TABLE 1 | Means, standard deviations, and correlations of the research variable.

\begin{tabular}{|c|c|c|c|c|c|c|c|c|c|}
\hline Variable & 1 & 2 & 3 & 4 & 5 & 6 & 7 & 8 & 9 \\
\hline \multicolumn{10}{|l|}{ Individual level } \\
\hline 1. Gender & 1.00 & & & & & & & & \\
\hline 2. Age & -0.07 & 1.00 & & & & & & & \\
\hline 3. Education & -0.03 & -0.11 & 1.00 & & & & & & \\
\hline 4. Employee's tenure & -0.01 & $0.65^{\star \star}$ & -0.06 & 1.00 & & & & & \\
\hline 5. Marriage & -0.02 & $0.15^{\star}$ & -0.03 & 0.07 & 1.00 & & & & \\
\hline 6. WCBA & 0.00 & -0.12 & -0.13 & -0.06 & -0.02 & 1.00 & & & \\
\hline 7. WFC & -0.02 & -0.06 & -0.12 & -0.00 & -0.01 & $0.90^{\star \star}$ & 1.00 & & \\
\hline 8. Psychological distress & -0.02 & -0.13 & -0.10 & -0.09 & 0.03 & $0.87^{\star \star}$ & $0.89^{\star \star}$ & 1.00 & \\
\hline 9. leader workaholism & 0.07 & 0.07 & $-0.16^{\star}$ & 0.05 & 0.09 & $0.69^{\star \star}$ & $0.75^{\star \star}$ & $0.69^{\star \star}$ & 1.00 \\
\hline M & 1.55 & 27.56 & 2.010 & 2.340 & 1.650 & 2.821 & 2.543 & 2.631 & 3.54 \\
\hline$S D$ & 0.50 & 3.19 & 0.4 & 2.196 & 0.690 & 0.907 & 0.918 & 0.743 & 1.16 \\
\hline Leadership level & 1 & 2 & 3 & 4 & 5 & 6 & & & \\
\hline 1. Gender & 1.00 & & & & & & & & \\
\hline 2. Age & $-0.16^{\star}$ & 1.00 & & & & & & & \\
\hline 3. Leader's education & 0.02 & -0.10 & 1.00 & & & & & & \\
\hline 4. Leader's tenure & -0.10 & $0.46^{\star \star}$ & -0.08 & 1.00 & & & & & \\
\hline 5. Marriage & 0.04 & $0.21^{* \star}$ & $0.17^{\star}$ & 0.07 & 1.00 & & & & \\
\hline 6. leader workaholism & 0.02 & 0.04 & -0.11 & 0.05 & -0.02 & 1.00 & & & \\
\hline M & 1.48 & 34.14 & 2.51 & 4.30 & 2.82 & 3.54 & & & \\
\hline$S D$ & 0.50 & 3.95 & 0.50 & 2.16 & 0.58 & 1.15 & & & \\
\hline
\end{tabular}

$N=211$. WCBA, work connectivity behavior after-hours; WFC, work-to-family conflict. ${ }^{*} p<0.05 .{ }^{* *} p<0.01$.

TABLE 2 | Fit indices of each model.

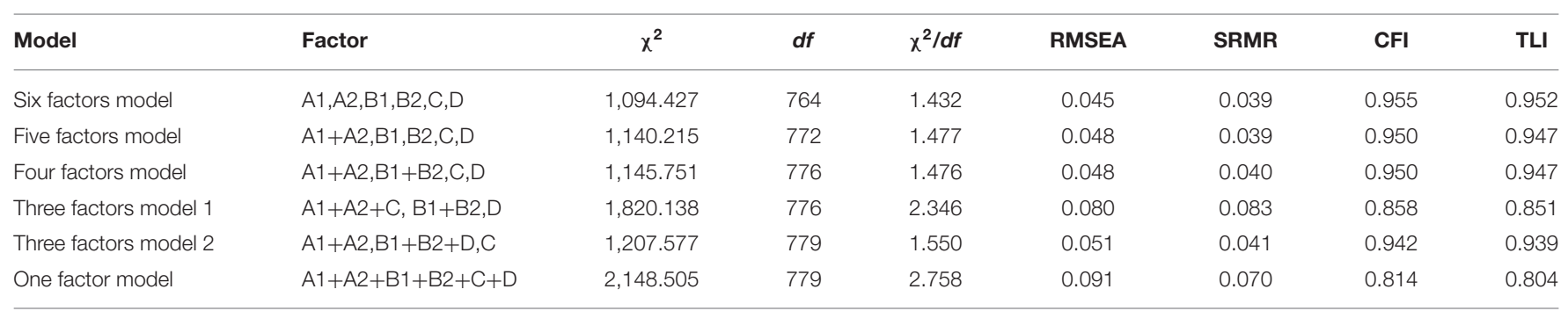

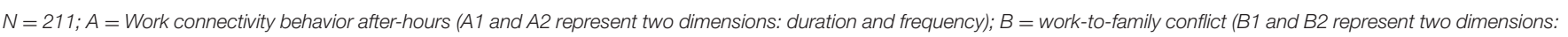
conflict over time and conflict overstress); $C=$ leader workaholism; $D=$ psychological distress.

Benbunan-Fich (19) who suggested collecting "lean" measures to capture activity (e.g., duration of use) and also "rich" measures that incorporate information about the nature of the activity (e.g., breadth of use, the context of use). Therefore, we collected selfreported measures of both duration (e.g., how much time they use the wireless devices) and frequency in context (e.g., how often they use the devices during particular non-work activities). Each item was measured on a 5-point Likert scale, ranging from 1, which indicates "never," to 5, indicating "always." First, we measured WCBA duration by asking respondents to report, on average, how much time they used each device (e.g., wireless email devices and laptops) to perform job-related duties during non-work hours. We collected responses for four time periods (e.g., before work, after work, during days off, and weekend and vacation). We provided response categories in ranges of minutes to create a Likert-type scale (e.g., 1-15 $\mathrm{min}, 16-30 \mathrm{~min}$, et al.).
The Cronbach's alpha was 0.830 . Second, to create a measure for WCBA frequency, we followed Boswell and Olson-Buchanan (20), who asked respondents to report the frequency (on a Likerttype scale) with which they used an array of communication technologies to perform their job during non-work hours. Their study responses to the individual technologies were averaged to create an overall index of reported communication technology use after hours. To improve the reliability of Boswell and Olson-Buchanan's measure, we first asked about the use of a specific technological device (e.g., handheld wireless devices, laptops) rather than the communication medium (e.g., sending and receiving work emails, contacting colleagues or customers, logging in to the company website, etc.), and then, we asked how frequently each device is used during a specific non-work activity (e.g., shopping, travel/vacation, dinner, reading, fitness, etc.). We averaged the responses to the individual technologies to create 
TABLE 3 | Summary of stepwise regression analysis.

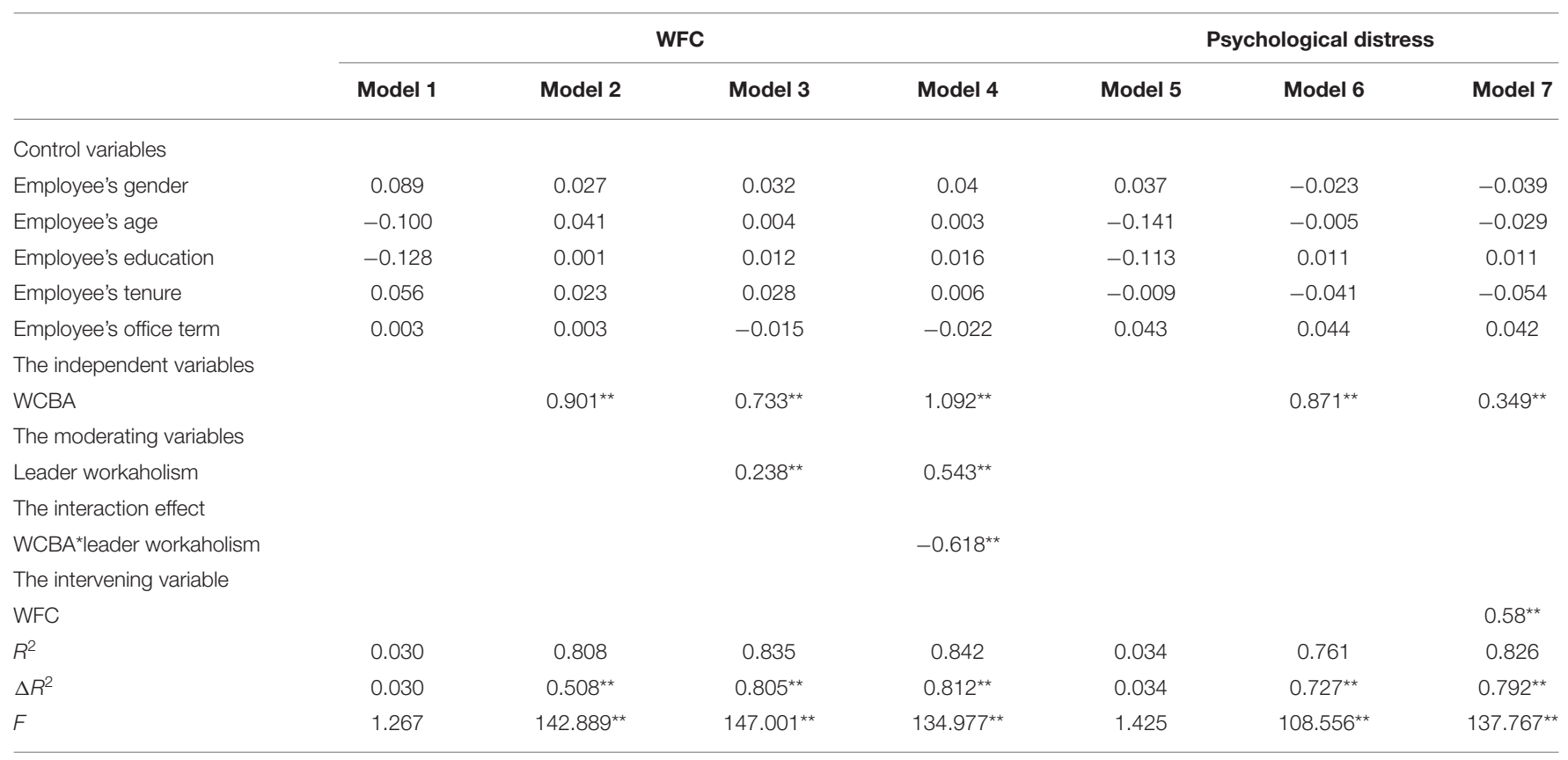

$N=211$. The regression coefficient $\beta$ is the standardized coefficient. ${ }^{* *} p<0.01$.

an overall index of WCBA frequency. The Cronbach's alpha was 0.914, and the Cronbach's alpha of the total scale was 0.933 .

\section{Leader Workaholism}

Workaholism was measured with a 10 -item scale from the Chinese version of She et al. (21) and the original English scale from Schaufeli et al. (22). Workaholism was operationalized by two scales: WE, as assessed with the 5-item Compulsive Tendencies Scale of the WART (23); WC, as assessed with the 5 -item drive scale of the WorkBat (24). Items were scored on a 5 -point rating scale, which ranges from 1 (totally disagree) to 5 (totally agree). Sample items were "racing against the clock, continue to work after colleagues left, many irons in the fire, more time working than socializing, doing two or three things at a time, important to work hard." Cronbach's alpha was 0.960 .

\section{Work-to-Family Conflict}

Work-to-family conflict was assessed using the four-point scale of Carlson et al. (25). Six items were used to measure WFC. Chinese scholar $\mathrm{Wu}$ et al. (15) stated that the items included subscale based on time conflict and subscale based on stress conflict. Sample items were "due to various pressures at work, sometimes even when at home, I am not in the mood to do what I like." Cronbach's alpha was 0.936 .

\section{Psychological Distress}

Psychological distress (PD) was measured by General Health Questionnaire (GHQ-12), which was widely used to measure the psychological distress (26). The scale asks whether the respondent has experienced a particular symptom or behavior recently. Each item is rated on a four-point scale (less than usual, no more than usual, rather more than usual, or much more than usual), and it gives a total score of 12 or 36 based on the scoring method selected. The most common scoring methods are bimodal (0-0-1-1) and Likert scoring (0-1-2-3). Since the latter produces a more acceptable distribution of scores for parametric analysis (less skewed and less kurtosis), we used the Likert scoring style for this study. A higher score indicates a lower degree of mental health, in other words, a higher degree of psychological distress. Cronbach's alpha was 0.945.

\section{Control Variables}

According to previous studies, we also collected the following demographic variables as control variables: age, gender, education level, and tenure $(4,27)$.

\section{Analytical Approach}

The software SPSS 24.0 was used to conduct fundamental analyses, which includes descriptive statistics and correlations for WCBA, WFC, psychological distress, and leader workaholism. All variables were computed, and descriptive statistics, namely mean $(M)$ and standard deviation $(S D)$, and correlations between variables were obtained. Mplus 7.4 software was used to establish structural equation models (SEMs). In this study, a bootstrapping analysis was conducted with WCBA as the independent variable, Psychological distress as the outcome variable, WFC as mediators, and leader workaholism as moderator, with 5,000 resamples to test a moderated mediation model and to calculate the $95 \%$ CIs. The number of subdimensions in each scale was unequal; thus, mean scores of the items were used for all observable variables in this study. 
TABLE 4 | The moderating role of leader workaholism.

\begin{tabular}{lcccccc}
\hline Variable & \multicolumn{2}{c}{ WFC } & & \multicolumn{2}{c}{ WFC } \\
\cline { 2 - 3 } \cline { 5 - 6 } & \multicolumn{1}{c}{$\boldsymbol{\beta}$} & $\boldsymbol{t}$ & & $\boldsymbol{\beta}$ & $\boldsymbol{t}$ \\
\hline WCBA & $0.73^{\star \star \star}$ & $18.62^{\star \star \star}$ & & $0.73^{\star \star \star}$ & $18.79^{\star \star \star}$ \\
Leader workaholism & $0.24^{\star \star \star}$ & $6.04^{\star \star \star}$ & & $0.16^{\star \star \star}$ & & $3.54^{\star \star \star}$ \\
Product interaction term & & & & $-0.12^{\star \star}$ & & $-3.02^{\star \star}$ \\
$R^{2}$ & $0.83^{\star \star \star}$ & & & $0.84^{\star \star}$ & \\
$F$ & $518.92^{\star \star \star}$ & & & $362.52^{\star \star \star}$ & \\
\hline
\end{tabular}

${ }^{\star *} p<0.01,{ }^{* * *} p<0.001$.

\section{RESULTS}

\section{Descriptive Results}

After eliminating incomplete and invalid questionnaires, 211 groups of valid matching data were finally collected. That is to say, 422 questionnaires were recovered with an effective response rate of $77 \%$. Participants come from Beijing, Guangzhou, Shanghai, and Hangzhou, where many concentrated Internet enterprises. The sample characteristics of subordinate employees are as follows: average age is 27.56 years $(S D=3.189)$, men account for $44.4 \%$, women account for $55.6 \%$. The average working year is 2.34 years $(S D=2.196)$. College degree or below accounts for $10.7 \%$, a bachelor's degree accounts for $78.6 \%$, and master's degree or above accounts for $10.7 \%$. The sample characteristics of direct leaders are as follows: average age is 34.14 years $(S D=3.947), 51.7 \%$ men and $48.3 \%$ women. The average working year is 4.3 years $(S D=8.354)$. College degree or below accounts for $0 \%$, a bachelor's degree accounts for $49.3 \%$, master's degree or above accounts for $50.7 \%$.

The average scores and the standard deviations of variables under study and their Pearson's correlations are presented in Table 1. Tenure was positively correlated with age $(r=0.65, p$ $<0.01$ ) but not with WCBA and WFC. WCBA was positively correlated with WFC $(r=0.90, p<0.01)$ and psychological distress of employees $(r=0.87, p<0.01)$. WFC was positively correlated with psychological distress $(r=0.89, p<0.01)$, which provided the basis for hypothesis testing. From the perspective of leadership, the age of leaders was positively correlated with their tenure, whereas leader workaholism was not correlated with the educational background, age, and marital status of leaders, but negatively correlated with the tenure of employees $(r=$ $-0.16, p<0.05)$. In addition, leader workaholism was positively correlated with WCBA $(r=0.69, p<0.01)$, WFC $(r=0.75, p$ $<0.01)$ and psychological distress $(r=0.69, p<0.01)$. Multiple regression analysis is needed to confirm further the relationship among the variables between the leader and employees at the crossorganizational level. The mean, standard deviation, and correlation coefficient of each variable are shown in Table $\mathbf{1 .}$

\section{Common Method Bias}

To test the extent to which the models are affected by common method bias, Harman's one-factor test was adopted. The goodness-of-fit index of one-factor model is as follows (See Table 2): $\chi^{2}=2,148.10, d f=799$, TLI $=0.804$, CFI $=0.814$,
SRMR $=0.070$. The goodness-of-fit index of six-factor model is as follows: $\chi^{2}=1,094.427, d f=764$, RMSEA $=0.045$, SRMR $=0.039$, CFI $=0.955$, TLI $=0.952$. The goodness-of-fit index of the six-factor model was far better than that of the one-factor model, which suggested that common method variance had less influence on this research. Besides, the six-factor model was far better than that of the other models as well, which suggested that our model has good discriminant validity.

\section{Stepwise Regression of the Study Variables}

Stepwise regression analysis was first conducted to test the hypothesizes, and Table 3 summarizes the result of the regression. We first entered control variables that include several demographic information. There is no significant impacts of age and gender on overtime work. The second step introduced WCBA and found that WCBA had a significant regression prediction for WFC $(\beta=0.901, p<0.01)$. In the third step, we introduced leader workaholism and found that the leader workaholism could significantly predict WFC $(\beta=0.238, p$ $<0.01$ ), and the regression coefficient between WCBA and WFC changed under the leader workaholism $(\beta=0.733, p<$ $0.01)$. The fourth step examined the interaction effect between WCBA and leader workaholism. The results showed that leader workaholism had a significant negative moderating effect on the relationship between WCBA and WFC, and the interaction term was significantly negative $(\beta=-0.618, p<0.01)$. Models 2 , 3 , and 4 combined to prove that leader workaholism played a weakening moderating role between WCBA and WFC, that is, with the increase of leader workaholism, the predicted value of WCBA to WFC decreased, which prove that hypothesis $3 \mathrm{a}$ is false and hypothesis $3 \mathrm{~b}$ is supported. Model 6 showed that WCBA could significantly positively predict the psychological distress of employees $(\beta=0.871, p<0.01)$, and Model 7 showed that WFC also significantly positively predicted the psychological distress of employees $(\beta=0.580, p<0.01)$, which confirms that WFC could play a mediating role in the relationship between leader workaholism and psychological distress of employees. Both Hypotheses 1 and 2 were supported.

\section{Moderating Effect Testing}

For the study's accuracy, the moderating effect test was then carried out. In addition, the product of the WCBA index and leader workaholism index was used as the interaction index, and the moderating effect of the product was tested. The results showed that the interaction between WCBA and leader workaholism could significantly predict WFC $(\beta=-0.12, p<$ $0.01)$, as shown in Table 4. F test showed significant regression equation $\left(R^{2}=0.84, F=362.52, p<0.001\right)$. A simple slope test was conducted, a moderating effect graph was made, and the results are shown in Figure 2. The slope of the interaction term was negative, which proves that leader workaholism had a weakening moderating effect in the relationship between WCBA and WFC. As the tendency of leader workaholism becomes higher, the positive correlation between WCBA and WFC still exists, but it is weaker than before. Hypothesis $3 \mathrm{~b}$ was supported again. 


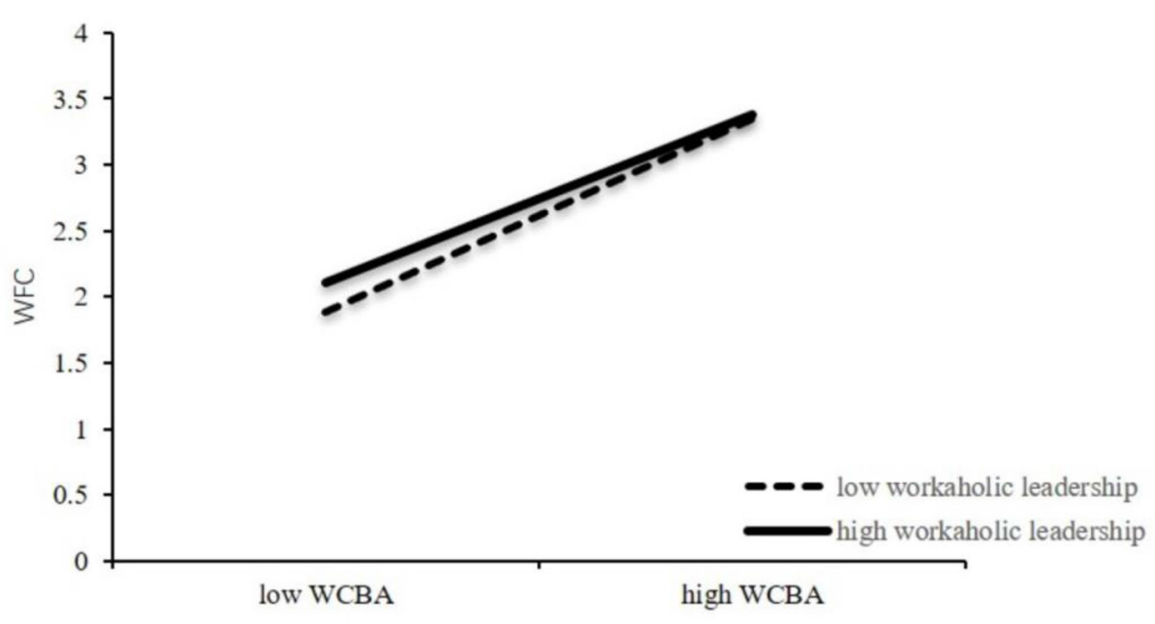

FIGURE 2 | The moderating effects of leader workaholism on WCBA and WFC.

TABLE 5 | The model fitting index of the mediating effect.

\begin{tabular}{llllllll}
\hline Model & $\chi^{2}$ & $\boldsymbol{d} \boldsymbol{f}$ & $\chi^{2} / \boldsymbol{d} \boldsymbol{f}$ & CFI & TLI & RMSEA & SRMR \\
\hline A & 394.70 & 272 & 1.45 & 0.97 & 0.96 & 0.05 & 0.04 \\
B & 630.22 & 430 & 1.46 & 0.96 & 0.96 & 0.05 & 0.04
\end{tabular}

\section{Mediating Effect Testing}

The mediating effect of WFC was tested by SEM using Mplus 7.4 with WCBA as an independent variable, employees' psychological distress as a dependent variable, and WFC as a mediator. Basic model A represents the direct effect of WCBA on employees' psychological distress, and Model B represents the effect of WCBA on employees' psychological distress with WFC as the mediator.

The model fitting index is shown in Table 5. The mediating model $($ model $\mathrm{B})$ fit well $(\mathrm{TLI}=0.96, \mathrm{CFI}=0.96$, RMSEA $=$ 0.05 , SRMR $=0.04$ ). Table 6 summarized the indirect effect test result. The direct and indirect effects of WCBA on employees' psychological distress were $0.306(p<0.001)$ and $0.628(p<$ 0.001 ), which account for $32.76 \%$ and $67.24 \%$, respectively, in the total effect. The results of the Bootstrap analysis show that the fitting data of the main models in this study are good. The Bootstrap analysis results showed that the $95 \%$ confidence interval of the path in Model B was [0.899, 0.976], excluding 0, which indicates a significant partial mediating effect of WFC on the WCBA-psychological distress relationship.

\section{Moderated Mediation Effects Testing}

Mplus7.4 was used again to justify the moderated mediation model with Bootstrap. WCBA path diagrams based on duration and frequency are shown in Figures 3, 4.

With arrows that indicate the direction in which the antecedent variable acted on the outcome variable, from the figure, we could see the direct effect and indirect effect among the variables, and the path coefficient represented the strength of the correlation between the variables.

However, only the path diagram was far from enough, and SEM fitting index test was a vital link. Based on generalized least squares estimation (GLS), the following indexes were used as the model fitting indexes: TLI $>0.9$, RMSEA $<0.08$, CFI $>0.9$, SRMR $<0.08$, which proves that the moderated mediating effect model in this study has a good fitting degree. Thus, Hypothesis 4 was supported. It was found that WCBA positively predicted WFC. With the increase of leader workaholism, the positive predictive effect of WCBA on WFC was weakened (but the two were still positively correlated), which might be related to the double characteristics of leader workaholism with high job requirements and high job involvement:

First, the high work requirements of workaholic leaders make workaholic leaders highly positively correlated with WCBA and WFC.

Second, the high work commitment of workaholic leaders provides resource support for employees. With the continuation of WCBA, workaholic leaders will provide more work support, such as providing problem-solving ideas and delegating colleagues to share the work, etc., which alleviates subordinate WFC.

Finally, whether from the perspective of high job requirements or high job involvement, the workaholic leader will provide work support and help to the subordinates to ensure the timely completion of the project. The higher the degree of workaholism, the more resource support employees get, which weakens the positive predictive value of WCBA to WFC. The research results are not only consistent with the resource conservation theory but also consistent with the research results of Pan (16).

\section{DISCUSSION}

This study reveals that WCBA can positively predict employees' psychological distress, and WFC plays a mediating role in the relationship between WCBA and employees' psychological 
TABLE 6 | Indirect effect of WFC.

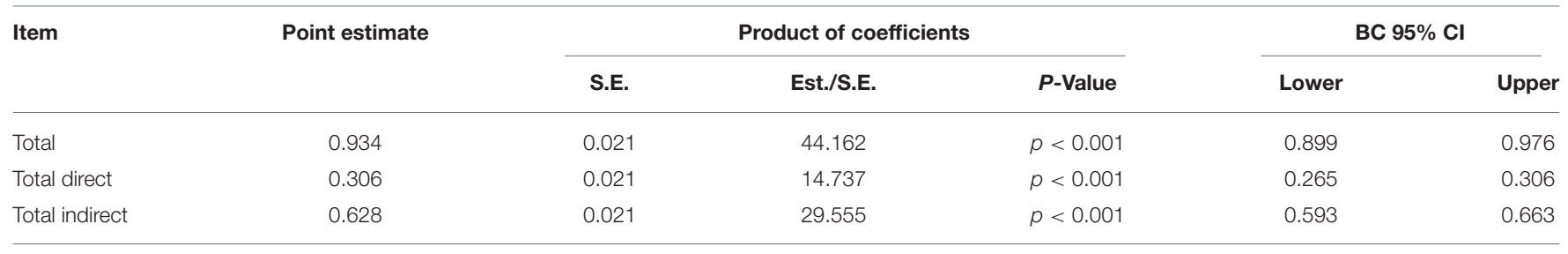

BC 95\% Cl, bias-corrected 95\% bootstrap confidence interval.

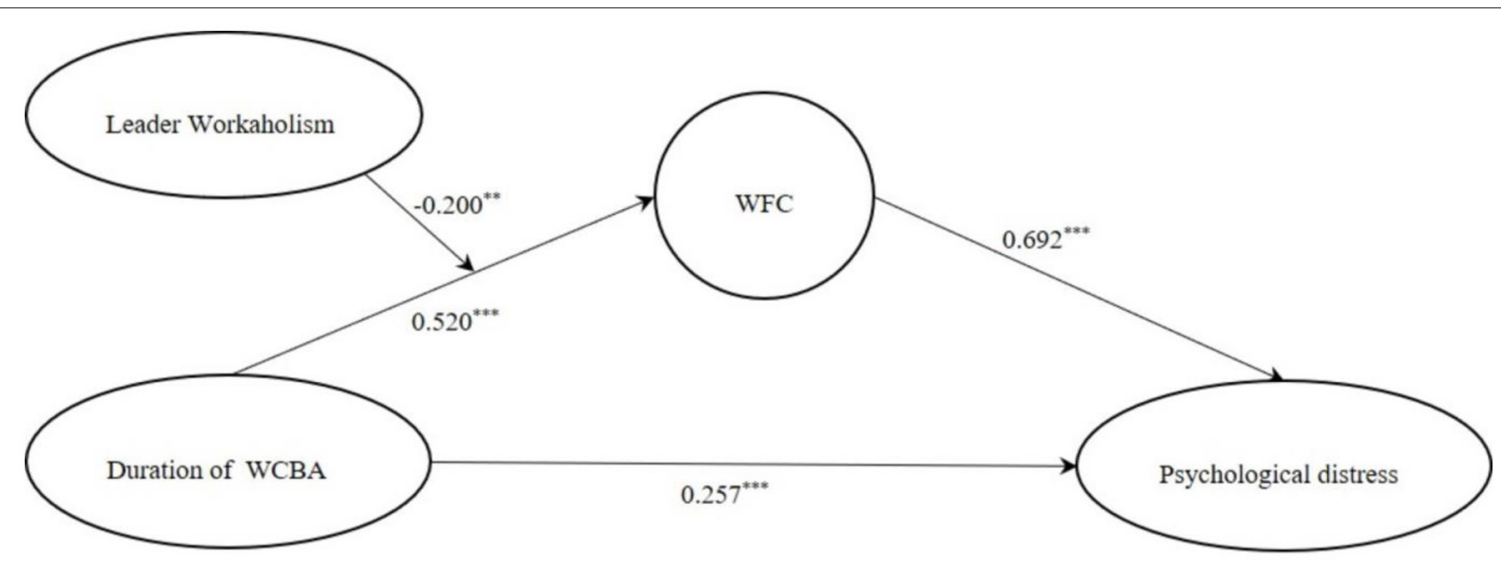

FIGURE 3 | Model path diagram based on the duration of WCBA.

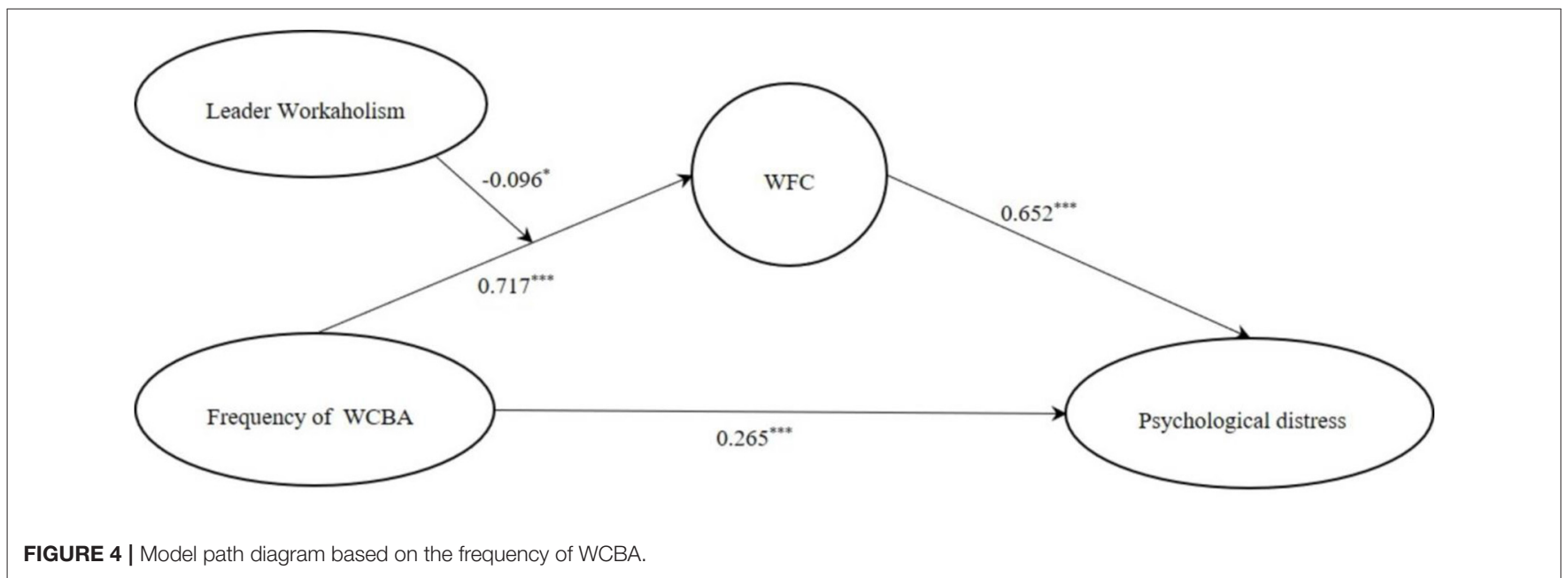

distress. Leader workaholism negatively moderates the relationship between WCBA and WFC. When the leader's workaholism tendency is high, the positive prediction of WFC on WCBA is weakened, and vice versa. Furthermore, leader workaholism moderates the indirect effect of WFC, that is, the indirect effect is stronger when the leader's workaholic tendencies are lower.

\section{Theoretical Implications}

First, we again verified that WCBA positively predicts employees' psychological distress, which is consistent with previous studies
(1-3). In addition, past questions about WCBA and psychological distress mechanisms have mainly been approached from the perspective of individual cognitions $(28,29)$. However, environmental factors, especially family environmental factors, are also essential for employees' mental health $(9,11)$. Therefore, we filled this gap by verifying the mediating effect of WFC in WCBA and individual psychological distress from the perspective of work-family boundary theory. Our findings expand the scope of work-family boundary theory in explaining organizational context factors and individual psychological distress. In the future, other variables of the work-family boundary can be 
further explored in the relationship of WCBA and employees' psychological distress, such as work-family balance. Finally, we explored the boundary conditions of this mechanism. We obtained an interesting finding that the degree of workaholism of the leader is an important moderator. When the degree of workaholism of the leader is high, it can weaken the predictive effect of WCBA on WFC, thus decreasing the negative predictive effect on employees' mental health. A leader's behavior and attitude to work can cause spread step-by-step and transfer to the subordinates. Our study further enriches the empirical research literature on the transmission effect of leadership.

\section{Practical Implications}

Our study showed the negative predictive effect of WCBA on employees' mental health. Therefore, at the individual level, individuals should participate in life activities appropriately after work, increase the transition activities between work and nonwork fields to promote psychological detachment, and maintain mental health. At the organizational level, managers should make reasonable use of human resource management theory, scientifically design the working process to avoid employees' WCBA, which is conducive to alleviating employees' job burnout (30).

We found that WFC is the mediating mechanism of predicting the effect of WCBA on employees' mental health. Thus, when some work tasks have to be done during family time, the company should give enough support to employees, especially the support to the family, to reduce the impact of work on the family. For example, the enterprise can hold family-orientation activities to give employees much more time to spend with family.

Leader workaholism will bring serious negative predictive effect on employees' physical and mental health, which is not conducive to the organization's long-term development. Interestingly, however, our findings suggested that leader workaholism negatively moderates the relationship between WCBA and WFC. It is the resources to complete the work from workaholic leader that weaken the negative predictive effect of WCBA; thus, leaders need to provide problem-solving resources during employees' non-working hours.

\section{Limitations and Future Research}

From the theoretical perspective, it is suggested to consider in the future: First, experimental design, such as laboratory experiments or intervention studies, should be introduced to clarify further the influence of WCBA on individuals and its mechanism of action. Second, we suggest that subsequent researchers combine field studies, quasiexperimental studies, case studies, and indepth interviews to explore the deeper relationship between WCBA and individual psychological distress or organizational performance. Third, in terms of data collection, on the one hand, longitudinal timing design should be combined; on the other hand, self-evaluation of the subjects should be combined with other objective evaluations, such as using the APP to record the time and frequency of WCBA. Fourth, we suggest considering the forced selection scale measurement to distinguish the workaholic and non-leader workaholism in the statistical analysis method. Last, considering that our results are based on the Chinses sample, cross country studies are needed to test the stability of our results.

From the empirical perspective, besides the moderating effect of leader workaholism, job characteristics and individual subjective will may also present the pathway function of nonworking time connecting to WFC. Considering only leader workaholism as a moderating variable is a little monotonous, which can be improved in the future. What is more, to enrich the transmission path between leaders and subordinates, more variables such as job characteristics (organizational assessment and workload) and leadership style (such as authoritative leadership) can be explored in the future.

\section{DATA AVAILABILITY STATEMENT}

The raw data supporting the conclusions of this article will be made available by the authors, without undue reservations.

\section{ETHICS STATEMENT}

The studies involving human participants were reviewed and approved by this study was carried out in accordance with the recommendations of the Ethics Committee of the Department of Psychology, Renmin University of China, with written informed consent from all subjects. All subjects gave written informed consent in accordance with the Declaration of Helsinki. The protocol was approved by the Ethics Committee of the Department of Psychology, Renmin University of China. The patients/participants provided their written informed consent to participate in this study.

\section{AUTHOR CONTRIBUTIONS}

MD designed and drafted the work. TZ made the main revision for the study and replied to reviewers. YL revised the original manuscript and the revisions. ZR collected the data. All authors contributed to the article and approved the submitted version.

\section{FUNDING}

The study was supported by Major Innovation and Planning Interdisciplinary Platform for the Double-First Class Initiative, Renmin University of China.

\section{ACKNOWLEDGMENTS}

We thank Ms. Huihui Chen for her helpful work in participating in data collection and providing valuable advice in revising the original manuscript.

\section{SUPPLEMENTARY MATERIAL}

The Supplementary Material for this article can be found online at: https://www.frontiersin.org/articles/10.3389/fpubh. 2022.722679/full\#supplementary-material 


\section{REFERENCES}

1. Gombert L, Rivkin W, Kleinsorge T, A. diary-study on work-related smartphone use and employees' well-being: the moderating role of basic need satisfaction. Zeitschrift für Arbeitswissenschaft. (2018) 72:11119. doi: 10.1007/s41449-017-0090-7

2. MacCormick JS, Dery K, Kolb DG. Engaged or just connected? Smartphones and employee engagement. Organiz. Dyn. (2012) 41:194-201. doi: 10.1016/j.orgdyn.2012.03.007

3. Ragsdale JM, Hoover CS. Cell phones during nonwork time: a source of job demands and resources. Comput Human Behav. (2016) 57:5460. doi: 10.1016/j.chb.2015.12.017

4. Ganster DC, Rosen CC. Work stress and employee health: a multidisciplinary review. J Manage. (2013) 39:1085-122. doi: 10.1177/0149206313475815

5. Li Z, Dai JM, Zhang D, Shu C, Wu N, Gao JL, et al. The effects of long working hours on occupational stress and depression in a state grid company. Chin J Ind Hygiene Occupat Dis. (2018) 4:271-74. doi: 10.3760/cma.j.issn.10019391.2018.04.009

6. Braukmann J, Schmitt A, Duranová L, Ohly S. Identifying ICTrelated affective events across life domains and examining their unique relationships with employee recovery. J Bus Psychol. (2018) 33:529-44. doi: 10.1007/s10869-017-9508-7

7. Sonnentag S, Fritz C. Recovery from job stress: the stressor-detachment model as an integrative framework. J Organ Behav. (2015) 36:S72S103. doi: $10.1002 /$ job. 1924

8. Richardson KM, Thompson CA. High tech tethers and work-family conflict: a conservation of resources approach. Eng Manage Res. (2012) 1:2943. doi: 10.5539/emr.vln1p29

9. Anderson SE, Coffey BS, Byerly RT. Formal organizational initiatives and informal workplace practices: Links to work-family conflict and job-related outcomes. J Manage. (2002) 28:787-810. doi: 10.1177/014920630202800605

10. Liang M, Chen JW. Compensation or autonomy: a study on the changing mechanism of internet technology embeddedness and work stress. Human Resour Develop China. (2017) 8:36-47.

11. Bilodeau J, Marchand A, Demers A. Work, family, work-family conflict and psychological distress: A revisited look at the gendered vulnerability pathways. Stress and Health. (2020) 36:75-87. doi: 10.1002/smi.2916

12. Bakker AB, Demerouti E, Burke R. Workaholism and relationship quality: a spillover-crossover perspective. J Occup Health Psychol. (2009) 14:2333. doi: $10.1037 / \mathrm{a} 0013290$

13. Butts MM, Becker WJ, Boswell WR. Hot buttons and time sinks: The effects of electronic communication during nonwork time on emotions and work-nonwork conflict. Acad Manag J. (2015) 58:76388. doi: 10.5465/amj.2014.0170

14. Andreassen CS, Hetland J, Molde H, Pallesen S. 'Workaholism' and potential outcomes in well-being and health in a cross-occupational sample. Stress Health. (2011) 27:e209-14. doi: 10.1002/smi.1366

15. Wu JQ, Zhang YF, Wang Z. Will employee work connectivity behavior afterhours cause work-family conflict? The effects of psychological detachment and organizational segmentation supplies. Human Resour Develop China. (2018) 35:43-54. doi: 10.16471/j.cnki.11-2822/c.2018.12.004

16. Pan SY. Do workaholic hotel supervisors provide family supportive supervision? A role identity perspective. Int J Hosp Manage. (2018) 37:5967. doi: 10.1016/j.ijhm.2017.09.013

17. Halbesleben JR, Ronald BM. Social comparison and burnout: the role of relative burnout and received social support. Anxiety Stress Coping. (2006) 19:259-78. doi: 10.1080/10615800600747835

18. Schaffer BS, Riordan CM. A review of cross-cultural methodologies for organizational research: a best- practices approach. Organ Res Methods. (2003) 6:169-215. doi: 10.1177/1094428103251542
19. Richardson K, Benbunan-Fich R. Examining the antecedents of work connectivity behavior during non-work time. Inf Organ. (2011) 21:14260. doi: 10.1016/j.infoandorg.2011.06.002

20. Olson-Buchanan JB, Boswell WR. Blurring boundaries: correlates of integration and segmentation between work and nonwork. $J$ Vocat Behav. (2006) 68:432-45. doi: 10.1016/j.jvb.2005.10.006

21. She Z, Li Q, Kong YC, Yang BY. Can workaholic leader promote follower job performance? The moderating role of follower work centrality. Human Resour Develop China. (2020) 37:44-55.

22. Schaufeli WB, Shimazu A, Taris TW. Being driven to work excessively hard: The evaluation of a two-factor measure of workaholism in the Netherlands and Japan. Cross-cultural research. (2009) 43:320-48. doi: 10.1177/1069397109337239

23. Robinson BE. The work addiction risk test: development of a tentative measure of workaholism. Percept Mot Skills. (1999) 88:199-210. doi: 10.2466/pms.1999.88.1.199

24. Spence JT, Robbins AS. Workaholism: definition, measurement, and preliminary results. J Pers Assess. (1992) 58:16078. doi: 10.1207/s15327752jpa5801_15

25. Carlson DS, Kacmar KM, Williams LJ. Construction and initial validation of a multidimensional measure of work-family conflict. J Vocat Behav. (2000) 56:249-76. doi: 10.1006/jvbe.1999.1713

26. Goldberg DP, Gater R, Sartorius N, Ustun TB, Piccinelli M, Gureje O, et al. The validity of two versions of the GHQ in the WHO study of mental illness in general health care. Psychol Med. (1997) 27:19197. doi: $10.1017 / \mathrm{S} 0033291796004242$

27. Harrison AW, Rainer RK. A general measure of user computing satisfaction. Comput Human Behav. (1996) 12:79-92. doi: 10.1016/0747-5632(95) 00020-8

28. Srivastava SC, Chandra S, Shirish A. Technostress creators and job outcomes: theorizing the moderating influence of personality traits. Inf Syst J. (2015) 25:355-401. doi: 10.1111/isj. 12067

29. Berg-Beckhoff G, Nielsen G, Larsen, EL. Use of information communication technology and stress, burnout, and mental health in older, middleaged, and younger workers-results from a systematic review. Int $J$ Occup Environ Health. (2018) 23:160-71. doi: 10.1080/10773525.2018. 1436015

30. Guenette JP, Smith SE. Burnout: job resources and job demands associated with low personal accomplishment in United States radiology residents. Acad Radiol. (2018) 25:739-43. doi: 10.1016/j.acra.2017. 12.002

Conflict of Interest: The authors declare that the research was conducted in the absence of any commercial or financial relationships that could be construed as a potential conflict of interest.

Publisher's Note: All claims expressed in this article are solely those of the authors and do not necessarily represent those of their affiliated organizations, or those of the publisher, the editors and the reviewers. Any product that may be evaluated in this article, or claim that may be made by its manufacturer, is not guaranteed or endorsed by the publisher.

Copyright $\odot 2022$ Dong, Zhang, Li and Ren. This is an open-access article distributed under the terms of the Creative Commons Attribution License (CC BY). The use, distribution or reproduction in other forums is permitted, provided the original author(s) and the copyright owner(s) are credited and that the original publication in this journal is cited, in accordance with accepted academic practice. No use, distribution or reproduction is permitted which does not comply with these terms. 